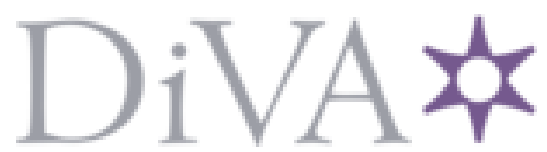

http://www.diva-portal.org

\title{
Postprint
}

This is the accepted version of a paper published in Journal of Organizational Change Management. This paper has been peer-reviewed but does not include the final publisher proof-corrections or journal pagination.

Citation for the original published paper (version of record):

Eriksson, Y., Fundin, A. (2018)

Visual management for a dynamicstrategic change

Journal of Organizational Change Management, 31(3): 712-727

https://doi.org/10.1108/JOCM-05-2016-0103

Access to the published version may require subscription.

N.B. When citing this work, cite the original published paper.

Permanent link to this version:

http://urn.kb.se/resolve?urn=urn:nbn:se:mdh:diva-39224 


\section{Visual management for a dynamic strategic change}

\section{Purpose}

Strategic changes in an organization will face challenges not only related to the changes as such but also with regard to how the vision of the future is interpreted and understood by the organization. Visual management is a field of research that could contribute to change management research as a means to facilitate management of the dynamics in a change process and to facilitate the process of communication. The purpose of this paper is to problematize episodic change processes with regard to communication and to contribute with a proposed model on how to facilitate dynamic strategic change management using visual management.

\section{Design/methodology/approach}

The paper uses an interdisciplinary approach by linking change management literature to visual communication to be used for visual management.

\section{Findings}

A proposed model presents how a dynamic episodic change process can be managed in terms of visual management, potential pitfalls to avoid, and what ambidextrous capabilities are needed throughout the complete episodic change.

\section{Research limitations/implications}

The proposed model is still yet theoretical, based on a literature review of dynamic change management and visual communication. Future research will validate the model in practice to confirm its robustness.

\section{Practical implications}

An implementation of visual management in Kotter's (1995) eight steps on how to strategically manage change in combination with theories on ambidexterity and episodic change is suggested.

\section{Originality/value}

The paper contributes to how visual management can support change management by combining visual communication and change management.

Key words: Visual Management, Change Management, Strategic planning, Visual Communication, Quality Management, Operations Management

Article classification: General review 


\section{Introduction}

Ideal strategic changes presuppose a dynamic process with a clear vision and welldefined aims and targets (Kotter, 1995). Strategic changes in an organization will face challenges not only related to the changes as such but with regard to how the vision of the future is interpreted and understood in the organization (Kyriakidou, 2011). Since strategic changes are long-term, they span over several years and frequently new strategic change processes are introduced at the end of a realization of the previous change process. To make change happen, which is often dependent on cultural and geographical variations, it is difficult to communicate with and involve all individuals in an organization and there are numerous of dilemmas that hinder the change process. Through conscious visualization of a strategy, the probability of reaching a common mental image of the future can be increased (Greif, 1991), but it will meet many challenges. Since a dynamic strategic change is process-oriented, it is necessary to avoid static visualizations (Whyte et al., 2007). Strategies tend to be perceived as objects and not as a living document.

By combining a strategy with a timeline a linear process is created, and at the same time the process is transformed into an object. As soon as something becomes an object, it is no longer internalized in a process. With a focus on the process for managing change, the aim of this paper is from a theoretical perspective to problematize the relation between dynamic strategic change initiated by a CEO and the management team and how to make the employees feel involved in the change through visual management. In addition, this paper explores the ability to consider change management as a dynamic design process that actively involves management teams and employees. The motivation for this literature review is to suggest that knowledge of visual management provides a potential to improve dynamic strategic change processes. As strategies are cyclical over limited periods, the context concentrates on episodic change processes as defined by Weick and Quinn (1999). In the theoretical discourse of ambidexterity in organizations (March, 1991; Raisch et al., 2009), the paper contributes to the research field of change management on how visual management could improve the ambidextrous capabilities in episodic change processes.

\section{Managing change through visual management}

Globalization is given high priority on the agenda in many companies today; new marketplaces promote possibilities to increase the number of products and services. One way to raise interest in and understanding of products and services is to combine information in texts with visuals, since visuals have the ability to give direct and concrete information. Visual culture is here defined in a broad sense including 2D pictures (photography, paintings, videos etc.) and 3D artefacts (built environment and people); how people act and dress is considerable for the visual culture. This has led to an increased interest in pictures (figurative and abstract symbols) as a tool for communication. This could be described as a pictorial turn (Mitchell, 1994), which is partly a reaction to the linguistic turn (Rorty, 1979). The linguistic turn proposes that language shapes the understanding of the environment, it emphasizes that meaning could only be understood through language (Rorty, 1979), while the pictorial turn suggests that visuals play a crucial role for understanding and communication. The challenge in change management strategy is to create a common meaning or at least an understanding of a future scenario; in other words, a shared reference is needed. By using visual communication it is possible to externalize a future scenario and to offer something visible and concrete (Tversky 2011). However, using pictures in an early stage of organizational change could also lead to a deadlock since what has been seen can never be unseen. 
The visual culture is a part of the visual communication and every culture has its own tradition; some parts are very local while others are more global. Even though visual media (television, film, photography, drawings etc.) is to a great extent global, the visual representations are often interpreted differently due to the individual cultures and experiences. However, as stated by several scholars (Mitchell, 2005a; Mitchell 2005b; Kress and van Leeuwen, 1996/2001; Sturken and Cartwright, 2009; Rose, 2011), one has to keep in mind that interpretation of visuals is a multimodal activity where several senses are involved. In addition, interpretation of visuals requires visual literacy. The meaning of visual literacy has been discussed over the last decades and there are variations of interpretations of the concept, but it could be explained as a capability to interpret, understand and use visuals in different situations (Dallow, 2008). To gain visual literacy, training is necessary since "images is not merely a picture, but involves social activity and interaction between people" (Kress and van Leeuwen, 1996). Frequent exposure of visual does not automatically lead to knowledge on how to interpret and use visual information from images of different kind.

Still, while opportunities are increasing so are the challenges. A company strategy that is meant to be operationalized in a global organization requires even more effort to know how to communicate a strategy, considering the many cultural aspects of global companies. In these companies visual management implies different probabilities of adoption by co-workers through, for example, symbols (Smith and Stewart, 2011), knowledge management approach (Staples et al., 2001), level of transferability (Bell and Davidson, 2013), intuition (Akinci and Sadler-Smith, 2012), life space of people (Burnes and Cooke, 2013), motion picture performance for strategic orientation (Hadida, 2009), and organizational space (Taylor and Spicer, 2007). One of the challenges is to create a common idea about the future goal; this could be defined as a shared reference. Not only different experiences and knowledge will have an effect on the mental image of the future, but also the many different cultures that strengthen the global presence of a company (Smith and Stewart, 2011). In order to create a shared understanding of the future, different strategies could be used. One strong target image of modern companies is to involve all co-workers and facilitate ways of utilizing the creativity of the many coworkers in the company towards a shared vision. Policy deployment or hoshin kanri (Jolayemi, 2008), Six Sigma (Aboelmaged, 2010), Total Quality Management (TQM) (Spencer, 1994) or Lean Production (Alves et al., 2012) are just a number of many different change management programs for cascading strategies into activities in order to involve all employees in a shared strategic focus. In these change management programs there are principles, such as built-in quality, customer focus and continuous improvement, that provide support for how the organization should work together; these principles are meant to support the operationalization and management of the selected change management program (Marodin and Saurin, 2013; Netland and Aspelund, 2013; Fullerton et al., 2014; Bortolotti et al., 2015; Netland et al., 2015). Furthermore, within the principles there are practices and tools to support sustainable change (Dean and Bowen, 1994).

Even if many companies face challenges of how to actually deploy these different programs, knowledge of how they can support strategy deployment in companies is growing, for example through use of different knowledge capabilities in companies (Staples et al., 2001). Still, even if companies have very well functioning programs for strategy deployment and communication of strategies, the challenge still remains of how to bring about a common target image and how to achieve a common understanding and shared view of not only a strategic focus and a vision of the company, but also why the company is taking a prioritized strategic direction (Styhre, 2010). Face-to-face 
communication no longer dominates communication acts, either in society or in larger companies and especially not in global companies. Instead different kinds of media are used for communication between individuals or individuals and groups. But it is not only communication between people and media that takes place; inter-media communication has a crucial impact. If the same information is presented in different media, such as text, images, or video, this will affect how the text (verbal or written) is interpreted. Likewise, the text will influence the understanding of images or video. But previous knowledge from information gained from one medium, now presented in a different way, will have an impact on the interpretation (Mitchell, 2005a).

The chosen medium and the design of the medium will have an impact on how the user perceives, decodes, understands, and uses the information. It is well known that communication is a process that takes time with, for example, frequent presentations, workshops, and dialogues in two-way communication between management teams, firstline managers, team leaders and co-workers (Barrett, 2002). There are many theories about communication, for a long time dominated by Shannon and Weaver's reference model from 1949 of communication (Shannon and Weaver, 1949). It is a linear one-way communication model that consists of five elements: source, transmitter, channel, receiver, and destination. However, communication is not a one-way process and conditions for communication are that the speaker and the listener understand each other because of a common ground (Clark, 1996). A challenge is to create a common ground in order to build conditions for possible communication. Communication acts have three fundamental dimensions. First, a temporal dimension; communication processes directly impact themselves. Second, a factual dimension; all communication processes require factual statements but they also require meta-statements to make communication understandable and targeted. Third, a social dimension; all communication processes are oriented towards others (Merten, 1976). A crucial part of communication is related to visual communication, which involves not only body language (Ropo and Parviainen, 2001), but also dress codes (Rafaeli et al., 1997).

\section{Building blocks for a dynamic strategic change}

The issue does not only concern when the strategy is cascaded as a means to achieve a shared reference of the future, but also understanding actual progress in the process when a strategy is operationalized, aiming at a shared view of the future result when different global initiatives are defined in terms of a mutual understanding of the future. To achieve a shared reference, the visualization of a strategy requires efforts across the complete strategic cycle and is also of importance when it is time to present and reflect on the actual results that a global company wants to reach. Visual management is not an established field but rather a combination of the two disciplines of change management and visual communication. Since the two disciplines offer different theoretical and methodical traditions, visual management has to be defined as interdisciplinary. In addition, they offer a range of variations individually. A theoretical approach to the interdisciplinary field that covers visual management with a focus on visual communication in combination with change management is required. A first step has been to define and justify what areas have to be taken into consideration when framing the topic.

In International Journal of Management Reviews, Bell and Davidson (2013) put forward that they "believe that the time is right for a visual turn in management studies as a means of generating new and interesting insights into management and organizations". How can a visual turn be realized in the context of management studies? From a visual studies point of view there are numerous theories that have to be taken into consideration when using visuals in organizations, especially if one wants to use visuals for decisions 
that will result in a shared reference of a future organization, product, or product system. Visuals and how they are designed affect the reception of knowledge and message in general. However, in which way a recipient perceives and interprets visuals has an impact on different kinds of decisions. Since images do not offer any specific reading direction or statement, they are arbitrary by nature. Research in Gestalt theories (Koffka, 1935), cognitive science (Ware, 2008; McCloud, 1993), and graphic design (Tufte, 1997), has elucidated how visual perception works in relation to attention, visual hierarchy, and the ability to direct a viewer's attention. These theories have an underlying assumption that the perceiver will find a direct correlation between the representation and the environment. But how and why an individual interprets a visual is based on previous knowledge and the mental image they have of the object or phenomenon that is represented. Even though the interpretations of visuals are individual and by that a deeper understanding of a representation is impossible to control, we will argue that it is still necessary to take theories of visual studies into consideration when designing visual artefacts for communication in organizations. But how the visuals are used and how they are verbalized in a communication act will have a crucial impact on the understanding of the representations on a semantic level (Krippendorff, 2006).

In order to understand how change management can benefit from dynamic strategic visual management, it is necessary to consider that visual management is culturally bound. It is therefore justified to combine theories from the fields of change management and visual communication to contribute to visual management for dynamic strategic change. It is known from previous research that visuals and especially photographs are co-creators of the identity of individuals and organizations (Styhre, 2010). At the same time, visuals are a way to present oneself as individual or as organization (Goffman, 1959/1990; Ropo and Parviainen, 2001; Rafaeli et al., 1997; Trethewey, 1999). Over the last decade, photographers have independently or in collaboration with companies been co-creators of people's understanding of manufacturing industries like Ford. Identity is closely related to identification. An organization's or a company's identity is something that employees often, or at least are expected to, identify themselves with. But what does it mean to identify oneself as an employee of a company? At a first glance, the question seems simple to answer but one has to take several aspects into consideration: the position of each employee in the company, the profession and the status or role of the profession in the company, the culture of the company, and the geographic location of the company and its role for the local society. Some towns or places are built on the foundation of a company and therefore the company could dominate the place and the employees could form an important community in the local society (Taylor and Spicer, 2007). Some places do have their heritage closely connected to the business of the place, such as a mining company or car manufacturer, industries associated with heavy work, dirt, and strong men. Today many of these manufactory processes are clean and the heavy work has been taken over by robots. When using visuals in dynamic strategic changes it is necessary to take all these aspects into consideration, the history of the company, its geographic site, professions and positions of the employees, and how these factors affect the identification with the company/organization and individual identity. A global company often has various positions in regard to the role it plays in local society in different parts of the world. For many professions and manufactory industries the union plays a significant role when it comes to the identity of blue-collar male workers, while women are secondary. As a consequence, there will be a contradiction in regard to how employees identify with the company in relation to management teams. But it is important to bring up the fact that the parties could identify strongly with the company but in different ways and for different reasons. Identity and identification often go back to the history of a company and the history of the geographic place. 


\section{Managing change across an episodic process}

Change management as a concept has been researched by many scholars since Lewin (1947) introduced the idea that changes can be planned by taking conscious steps considering the role of life spaces as boundaries for changes in social contexts. A few years later Lewin (1951) introduced a process of three steps that has influenced change management research over many decades; planned changes were described through a process of unfreezing the current state, moving towards a future state and finally freezing the new state. An interesting review of Lewin's field theory was presented by Burnes and Cooke (2013), putting forward field theories as theories that also acknowledge individuals and groups to explore how the world is perceived (Burnes and Cooke, 2013). They further emphasize that if there is no common understanding of the current state, there is no room for making change happen at all. Many years after Lewin, one of the most referred researchers in the field of change management is John Kotter; see, for example, Kotter (1995). After his introduction of the eight-step model for change, it has been a guide for many companies, not only on how to successfully manage change but also what pitfalls to avoid (Kotter, 1995; Kotter 2007). The eight steps are: Establishing a sense of urgency, forming a powerful guiding coalition, creating a vision, communicating the vision, empowering others to act on the vision, planning for and creating short-term wins, consolidating improvements and producing still more change, and institutionalizing new approaches. Since the research work by John Kotter, research has presented numerous supplementary methods, steps, and concepts of how to manage change in organizations. For example, important practical steps (Jørgensen et al., 2009), themes and success factors (Oakland and Tanner, 2007), process pattern and success factors (Ford and Greer, 2006), hard key factors (Sirkin et al., 2005), facilitating practices of employee development (Proctor and Doukakis, 2003), success factors (Kotter and Cohen, 2002), 12-step model for change (Mento et al., 2002), two theories of change (Beer and Nohria, 2000), eight initiatives (Gigleous and Gigleous, 2001), and four rules (Denton, 1996). Some approaches are strongly linked to each other, while some are found to be more supplementary (Sannö et al., 2016). A common denominator of importance in the research, however, is that all are approaches to how to reach a common understanding about, first, the current state of an operation, and second, a future attractive state shaped as a vision to strive towards. However, the eight steps have never been discussed with respect to visual management. The eight-step change process is a well-described example of an episodic change process using the definition by Weick and Quinn (1999) with characteristics of infrequency, discontinuity, and being intentional. The duality of episodic change is described by the same authors as continuous change processes characterized by being ongoing, evolving, and cumulative (Weick and Quinn, 1999).

After all, it seems that more research is needed to get under the skin of change, using the words by Hallencreutz (2012). Hallencreutz studies what is the actual meaning of different change management models when adopted by management teams and organizations initiating a change. The research shows that the theory is still in motion and it is very difficult to find best practice examples. It seems that one has to revert back to the research by Kurt Lewin and the comment by Burnes and Cooke (2013) on how to make a common understanding of current state as a prerequisite to making a planned change and transformation start in the first place. Still, there are many factors that influence whether or not change management programs will be successful and that make the research on change management in organizations even more difficult. The research area of visual management is still immature and theories presented in the field of change management could benefit from theories in visual communication. The question is whether the strategy is competitive enough, and if it is, longitudinal research studies are 
needed to study the actual effect of the change from an executed competitive strategy at hand (Hutzschenreuter and Israel, 2009). Likewise, it is only longitudinal research studies that are able to study the effect of ambidextrous capabilities in organizations.

\section{Ambidextrous capabilities in strategy formulation and communication}

Organizational ambidexterity has been a research topic for some years and the interest seems to increase (Gupta et al., 2006; Raisch et al., 2009). In this discourse of research, change processes are building blocks for organizational learning and prerequisites to fostering an innovative climate. Building on theories by James March, an important distinction is made between exploration and exploitation (March, 1991); explorative strategic change processes aim at future product or service solutions, while exploitative processes concern execution and refinement of existing processes. These ideas are further explored in change management theories aiming to find a balance and a dynamic between the concepts of exploration and exploitation (Gupta et al., 2006); in other words, organizations face challenges in being ambidextrous when managing speed of change (Raisch et al., 2009). Ambidextrous capabilities of an organization are capabilities for strategically managing dichotomies simultaneously such as, for example, differentiation and integration, individual and organization, static and dynamic, and internal and external (Raisch et al., 2009). From a strategy formulation perspective, managing dichotomies simultaneously is not an easy task; organizations strive for exploitation and execution of current strategies while at the same time formulating explorative strategies for the future, and formulation of a new strategy and execution of a current one requires a number of ambidextrous capabilities.

Managing an episodic change through strategy formulation and strategy execution simultaneously raises a number of questions and challenges such as how to balance differentiation and integration of an ongoing exploitative strategy execution in later phases of an episodic change process with the task of formulating a new explorative strategy for the future. What does this imply for an individual manager formulating new strategies while an organization is simultaneously implementing a currently ongoing strategy execution program? Following the pathways towards ambidexterity, an episodic change process requires a balance between being static and dynamic (Raisch et al., 2009). This challenge arises not only within the current strategy formulation process through different steps but also as a challenge between different episodes of change. Consequently, being ambidextrous poses a number of challenges for both individuals and organizations, and what individuals feel, see, and understand in a strategy is very much affected by the use of visuals, certainly in a strategy formulation process, and by how a change process is managed. Visuals could, however, be both supportive and harmful in a change process; they have to be consciously used throughout and between the different episodes of change.

\section{Bridging visual management through an episodic change management process}

Visualizations in change management constitute an image to facilitate planning of future changes. Paradoxically, even though the visual representations are used operatively they are often not designed according to principles for visual theory or visual communication or for specific occasions and purposes. Instead the visuals that are used are often dependent on the software or on pre-designed symbols and pictures in PowerPoint presentations. Dynamic qualitative change management cannot be founded on a static image of the future, it is dependent on a strong vision that the majority of employers agree upon or at least accept. At the same time it has to be flexible in order to fulfil the demands of being dynamic. It is necessary to know and understand what mechanisms need to be supported to push the change in the intended direction. Therefore, it is 
important to delimit the action plan and make a clear definition of the expected result of the change management and visual communication in order to combine the theories in a fruitful way. However, visualizing a strategy requires ambidextrous abilities among the users since the visuals need to promote the vision in a specific way to support the ability to build a shared reference of the future and at the same time have a level of both concretization, that support the understanding, and abstractions, that enables individual interpretations. But the individual interpretations have to be aligned with the mutual mental understanding of the future.

Building on the eight steps defined by Kotter (1995) as a guideline for initiating and managing change, the following analysis proposes a further explored model by adding visual management, in this way contributing to the literature in visual management by linking it to the research field of change management. According to Kotter one should start by establishing "a sense of urgency. Examine market and competitive realities for potential crises and untapped opportunities. Convince at least $75 \%$ of your managers that the status quo is more dangerous than the unknown." He emphasizes the importance of not underestimating the difficulty of driving people from comfort zones.

Visualization of stage 1 builds on the identity of the company in order to convince employees about the urgency in the current stage. One option could be to illustrate with a picture that underlines unity with the company and pride in its products. What is suitable to emphasize in the illustration of the current stage depends on what has to be changed in the company like, for example, the organization, the products, old products replaced by new, or plant relocation. Today there is a change in focus from the product itself to the lifecycle of the product including service of products. Not only the quality of the product is therefore highlighted, the service the customer can expect will also be in focus. In this way the producer will indirectly uncover weak parts of the product that probably need to be improved. A picture could be a photograph of the products in combination with a graph showing the expected results in the future, on an abstract level, followed by a picture that shows a week part, combined with the number of parts that fail over time. To clarify the urgent situation, it is necessary to define and highlight the identity of the company, the strength of the product/service, and what might jeopardize the company's market position. This has to be visualized in a way that it is possible for the employee to identify with the image and to grasp the urgency. The possibility to feel aligned with the company and be proud of the products/service will drive the employees from their comfort zone. The visuals used in the first stage need to be consistent throughout the eight steps.

In stage 2 Kotter brings up the need for a powerful and guiding coalition. What images will the employees adopt from the guiding coalition? How will they perform according to dress codes and interaction between each other in public or in relation to the employer? Mimic and gesture can play a crucial role in this step. Visuals are a part of a visual culture, which includes the environment and people who interact in it and with each other. Visual culture perspectives require systems thinking; how the vision of the strategy is visualized needs to correspond with people involved and the contexts. It is an intricate balance between a current state and a desired state of the future but also between the guiding coalition and the employees in an organization when it comes to how they act, behave, and dress (including accessories and jewelleries). Global organizations need to deal with several geographically distributed cultures (ethnicity, religion, language) and the culture of the company.

In stage 3, when creating a vision and using visualizations, these must be in line with the identity of the company. The discrepancy between a current stage and what is expected from the change strategy must correspond with the vision and the visuals, and 
the verbal description and presentations need to correspond to them. It is not possible to use old images that have been used previously in the organization for other purposes.

Stage 4 is closely linked to the previous stage; how the vision is visualized needs to be closely connected with how it is communicated. If the change is communicated as a process, it is important that it is visible, but the visualization needs also to show the final stage. This part requires ambidextrous abilities of the one who formulates the vision, of the designer of the visuals, and of the employees. The coalition group needs to have the capability to guide the employees in how to interpret the visuals in relation to the verbal definition of the vision but at the same time be open for alternative interpretations made by the employees and include these interpretations in the discussion and not only in the discussion but also to firmly establish alternative interpretations in the visuals. Even if the visuals of the vision are the same throughout the complete episodic change process, which they have to be, the use of the dialogue and the interpretation needs to vary over time. If not, the visuals will be objects and not supporting tools for a change process. By having a clear visualization of the vision that matches the content of the vision, it is possible to gain a common vision of the future. The image should not be too detailed, nor should it be too abstract. If the pictures are clear and at the same time open for employees' own interpretations and they use it as a basis for continuous discussions, this will support the possibilities for successful change. Change is looked upon here as a process, and the procedure must be visible in the visualizations. The history of an organization or a company is continually recorded in annual reports. Various kinds of visuals are often used in these, such as graphs that show results combined with abstract drawings of the activities, but also photographs. The annual report constitutes the image of the organization and of the employees in different positions and with different professions. These reports could be a good starting point for a new strategy, but if the visuals from previous reports are used for picturing the future, the idea of a strategic change will be severely weakened. Visual management is primarily a top-down process in which the CEO together with a manager team creates a vision. The aim of visual management is to convince the employees of the need for change in the organization and at the same time involve them and have them contribute to a vision. From this point the individual thinking by the CEO has to be understood by the management team, and further on the employees' thinking must be stimulated. A common image of the vision is needed and then the strategy for the realization of the vision has to be established in the organization. This is the critical part, how to use visual management in a way that it fulfils the intention and allows a dynamic process at the same time. The organization's identity and history must be combined with the identity and history of the different professions in order to make a dynamic strategic change by using visual management. Since visual management is a combination of visual communication and management, vision and visibility need to be considered to play a decisive role in the organization of space (Styhre 2010). How a manager acts while giving presentations as well as how the design of visuals in presentations appears and how they are used is part of the visual management.

Stage 5 emphasizes the possibilities to imitate; this could be behaviour or a way to style a room or oneself. Visuals that portray individuals or environments are mimetic, which means it is possible to imitate them. It is not always necessary for the one who imitates to know or understand the intended aim of the pictures. Interestingly, the imitation as such could lead to an internalization of the behaviour and by that be embedded in the individual. When the lean production system together with $5 \mathrm{~S}$ was implemented in manufacturing companies in Europe, it was discussed whether it is possible to take a philosophy from another culture and use it more or less mechanically. Lean production goes together with a kind of visual management, as it is easy to copy and 
to imitate. From the imitation it has slowly become internalized in many employees' behaviour; what is expected is visible to every single individual.

In stage 6 Kotter brings up the necessity to show short-term wins, but this must not be mixed up with the final target. To visualize short-term wins as a part of the final target is challenging and needs to be problematized in relation to the purpose of showing shortterm wins.

In line with stage 6, stage 7 needs to follow the same track as the previous one, but this stage must also point out some progress. Since visuals have a considerable impact on human beings, it is obvious that change management can benefit from visual management when cultural aspects, for example company, geography, or gender, are taken into consideration. Visuals make it possible to portray things and to show relations and by that render abstract thoughts and phenomena tangible. A picture of a current or previous state could be used as a basis for discussion, and single individuals can agree or voice a different opinion about its feasibility, but that is not the case when it comes to an image of the future. The only thing that is possible to agree or disagree on is the vision and strategy itself and, of course, whether it is visualized in a way that fits the strategy.

Finally, in stage 8 , visuals of the new state has to be in line with the previously visualized vision and at the same time expand and be more detailed regarding the institutionalization. To keep momentum in the change process, the visualization must not depart from the previous design; visual management would in this way create an important building block in the communication and uncover the missing link between current and future states. This would provide a potential to facilitate dynamics in strategic change processes.

The suggested implementation of visuals in Kotter's 8-step model requires a deeper understanding of how to support the interpretation of the visual representation. Since visual literacy is an active learning process the change management team need to find strategies for how to assist the co-workers with necessary tools for interpretation of the visuals. In intercultural contexts this is crucial. Since the content of a visual representation is affected by which media or technic (drawing, video, photography etc.) that is used it is important to validate that the information do not differ between media. The inter-mediated relation must be clear, and image and text must provide the same message.

\section{Proposed model to facilitate dynamic strategic change}

As a means to facilitate dynamic strategic change management, by linking to literature in visual communication to be used for visual management, our research proposes a model built on Kotter's (1995) eight steps. The proposed model describes how visual management can be utilized considering needs of ambidextrous capabilities. If change is considered as episodic, the eight steps suggested by Kotter will be repeated periodically during a dynamic strategic change process. An episode of change comprises the eight stages and there is a need to link those in order to create an overall image of the coming dynamic strategic changes. This requires ambidextrous capabilities among the initiators as well as in the organization; by using visuals to materialize the various phases and the different stages, the ambidextrous capability could be increased. In dynamic strategic visual management for change management the challenge is to be aware of the organization's identity, the current stage, how it changes over time and the actual meaning of the actual change management models adopted by those initiating a change. Three important ambidextrous capabilities are projected in the model: managing change in each stage (A1), managing change in the transformation between stages (A2), and managing change between episodic change processes (A3); see Table 1. 
Table 1. Building on the theories by Kotter (1995), a proposed elaborated model to facilitate dynamic strategically change with guiding principles for visual management through different levels of abstraction. Three important ambidextrous capabilities are projected in the change management process: Managing change within each stage (A1), managing change in the transformation between stages (A2), and managing change between episodic change processes (A3).

\section{Discussion and conclusions}

The literature review of the research field of visual management indicates that a multidisciplinary approach is required, both in theory and in practice. Visual management is still an immature field of research and needs to be considered with care and not only by introducing visual aspects as such in management theories. The review shows several well-written overviews of research in visual communication; however, these are still not interlinked with the management literature and certainly not with a change management perspective, while theories for visualizing implementations are missing except for how to visualize improvement work in lean production systems. The other way around, visual communication focuses on social and cultural contexts, and there are no studies focusing on management and industrial contexts. Combining competences from change management with visual communication will enable a multidisciplinary approach and redefine problems arising from common boundaries in order to reach solutions based on a new understanding of complex situations.

From a change management perspective, the literature review and the model provides new in-depth approaches to how to consciously manage change. Visual communication contributes to the way of how to continuously manage communication throughout a complete episodic change process. Furthermore, carefully nurturing the different ambidextrous capabilities in the change process would potentially encourage government of the change. The aim of the proposed model is to narrow down theories of visual communication to focus on how they can be applied to change management that takes ambidextrous capabilities and episodic change into consideration. The proposed model is still yet theoretical, based on a literature review of dynamic change management and visual communication. Future research will validate the model in practice to confirm its robustness.

\section{Acknowledgments}

This research work is a part of the initiative for Excellence in Production Research (XPRES), a cooperation between Mälardalen University, the Royal Institute of Technology, and Swerea. XPRES is one of two government-funded Swedish strategic initiatives for research excellence in production.

\section{References}

Aboelmaged, M.G. (2010), "Six Sigma quality: a structured review and implications for future research", International Journal of Quality \& Reliability Management, Vol. 27, No. 3, pp. 268-317. 
Akinci, C. and Sadler-Smith, E. (2012), "Intuition in Management Research: A Historical Review", International Journal of Management Reviews, Vol. 14, No. 1, pp. 104-122.

Alves, A.C., Dinis-Carvalho, J. and Sousa, R.M. (2012), "Lean production as promoter of thinkers to achieve companies' agility", The Learning Organization, Vol. 19, No. 3, pp. 219237.

Arnheim, R. (1969/1984), Visual Thinking, University of California Press Berkeley, CA.

Barrett, D. J. (2002), "Change communication: using strategic employee communication to facilitate major change", Corporate Communication: An International Journal, Vol. 7, No. 4, pp. 219-231.

Beer, M. and Nohria, N. (2000), "Cracking the Code of Change", Harvard Business Review, Vol. 78, No. 3, pp. 133-141.

Bell, E. and Davison, J. (2013), "Visual Management Studies: Empirical and Theoretical Approaches", International Journal of Management Reviews, Vol. 15, No. 2, pp. 167-184.

Bortolotti, T., Boscari, S. and Danese, P. (2015), "Successful lean implementation: Organizational culture and soft lean practices", International Journal of Production Economics, Vol. 160, pp. 182-201.

Burnes, B. and Cooke, B. (2013), "Kurt Lewin's Field Theory: A Review and Re-evaluation", International Journal of Management Reviews, Vol. 15, No. 4, pp. 408-425.

Clark, H.H. (1996), Using Language, Cambridge University Press, Cambridge, UK.

\section{Dallow, P. (2008), "The Visual Complex: Mapping Some Interdisciplinary Dimension of Visual Literacy", in Elkins, J. (Ed.), Visual Literacy, Routledge, London/New York, pp. 91-104.}

Dean Jr., J.W. and D.E. Bowen (1994), "Management theory and total quality: improving research and practice through theory development", Academy of Management Review, Vol. 19, No. 3, pp. 392-418.

Denton, D.K. (1996), "Four simple rules for leading change", Empowerment in Organizations, Vol. 4, No. 4, pp. 5-9.

Ford, M.W. and Greer, B.M. (2006), "Profiling Change: An Empirical Study of Change Process Patterns", Journal of Applied Behavioral Science, Vol. 42, No. 4, pp. 420-446.

Fullerton, R.R., Kennedy, F.A. and Widener, S.K. (2014), "Lean manufacturing and firm performance: The incremental contribution of lean management accounting practices", Journal of Operations Management, Vol. 32, No. 7-8, pp. 414-428.

Gilgeous, V. and M. Gilgeous (2001), "A survey to assess the use of a framework for manufacturing excellence", Integrated Manufacturing Systems, Vol. 12, No. 1, pp. 48-58.

Goffman, E. (1959/1990), The Presentation of Self in Everyday Life, Anchor Books/London, UK, Penguin, New York, NY.

Grief, M. (1991), The Visual Factory: Building Participation Through Shared Information, Productivity Press, Portland, OR.

Gupta, A.K., Smith, K.G. and Shalley, C.E. (2006), "The Interplay between Exploration and Exploitation", Academy of Management Journal, Vol. 49, No. 4, pp. 693-706. 
Hadida, A.L. (2009), "Motion picture performance: A review and research agenda", International Journal of Management Reviews, Vol. 11, No. 3, pp. 297-335.

Hallencreutz, J. (2012), Under the Skin of Change: Meanings, Models and Management. PhD Thesis. Luleå University of Technology, Luleå, Sweden.

Hutzschenreuter, T. and Israel, S. (2009), "A review of empirical research on dynamic competitive strategy", International Journal of Management Reviews, Vol. 11, No. 4, pp. 421461.

Jolayemi, J.K. (2008), "Hoshin kanri and hoshin process: A review and literature survey", Total Quality Management \& Business Excellence, Vol. 19, No. 3, pp. 295-320.

Jørgensen, H.H., Owen, L. and Neus, A. (2009), “Stop improvising change management!”, Strategy \& Leadership, Vol. 37, No. 2, pp. 38-44.

Koffka, K. (1935), Principles of Gestalt Psychology, Lund Humphries, London, UK.

Kotter, J.P. (1995), "Leading Change: Why Transformation Efforts Fail”, Harvard Business Review, March-April, pp. 1-10.

Kotter, J.P. (2007), "Leading Change: Why Transformation Efforts Fail”, Harvard Business Review, Vol. 85, No. 1, pp. 96-103.

Kotter, J.P. and Cohen, D.S. (2002), "Creative ways to empower action to change the organization: Cases in point", Journal of Organizational Excellence, Vol. 22, No. 1, pp. 7382 .

Kress, G. and van Leeuwen, T. (1996), Reading Images: The Grammar of Visual Design, Routledge, London.

Kress, G. and van Leeuwen, T. (2001), Multimodal Discourses. The Modes and Media of Contemporary Communication, Hodder Arnold Publication, London.

Krippendorff, K. (2006), The Semantic Turn - A New Foundation for Design, CRC Press, Boca Raton, FL.

Kyriakidou O. (2011), "Relational perspectives on the construction of meaning", Journal of Organizational Change Management, Vol. 24, No. 5 pp. 572 - 592.

Lewin, K. (1947), "Frontiers in Group Dynamics: Concept, Method and Reality in Social Science; Social Equilibria and Social Change", Human Relations, Vol. 1, No. 1, pp. 5-41.

Lewin, K. (1951), Field Theory in Social Science: Selected Theoretical Papers, Harper \& Brothers, New York, NY.

March, J.G. (1991), "Exploration and Exploitation in Organizational Learning”, Organization Science, Vol. 2, No. 1, pp. 71-87.

Marodin, G.A. and Saurin, T.A. (2013), "Implementing lean production systems: research areas and opportunities for future studies", International Journal of Production Research, Vol. 51, No. 22, pp. 6663-6680.

McCloud, S. (1993), Understanding Comics: The Invisible Art, Kitchen Sink Press, New York, NY.

Mento, A., Jones, R. and Dirndorfer, W. (2002), “A change management process: Grounded in both theory and practice", Journal of Change Management, Vol. 3, No. 1, pp. 45-59.

Merten, K (1976), "Reflexivität als Grundbegriff der Kommunikations Forschung", Publizistik, Vol. 21, pp. 171-179. 
Mitchell, W.J.T. (1994), Picture Theory: Essays on Verbal and Visual Representation, University of Chicago Press, Chicago, IL.

Mitchell, W.J.T. (2005a), What Do Pictures Want? The Lives and Loves of Images, University of Chicago Press, Chicago, IL.

\section{Mitchell, W.J.T. (2005b), "There are No Visual Media", Journal of Visual Communication, Vol. 4, No. 2, pp. 257-266.}

Netland, T.H. and Aspelund, A. (2013), "Company-specific production systems and competitive advantage: A resource-based view on the Volvo production system", International Journal of Operations \& Production Management, Vol. 33, No. 11/12, pp. 1511-1531.

Netland, T.H., Schloetzer, J.D. and Ferdows, K. (2015), "Implementing corporate lean programs: The effect of management control practices", Journal of Operations Management, Vol. 36, pp. 90-102.

Oakland, J.S. and Tanner, S. (2007), "Successful Change Management", Total Quality Management \& Business Excellence, Vol. 18, No. 1-2, pp. 1-19.

Proctor, T. and Doukakis, I. (2003), "Change Management: the role of internal communication and employee development", Corporate Communication: An International Journal, Vol. 8, No. 4, pp. 268-277.

Rafaeli, A., Dutton, J., Harquail, C. V. and Mackie-Lewis, S. (1997), "Navigating By Attire: The Use of Dress by Female Administrative Employees", Academy of Management Journal, Vol. 40, No. 1, pp. 9-45.

Raisch, S., Birkinshaw, J., Probst, G. and Tushman, M.L. (2009), "Organizational Ambidexterity: Balancing Exploitation and Exploration for Sustained Performance" Organization Science, Vol. 20, No. 4, pp. 685-695.

Ropo, A. and Parviainen, J. (2001), "Leadership and bodily knowledge in expert organizations: epistemological rethinking”, Scandinavian Journal of Management, Vol. 17, No. 1, pp. 1-18.

Rorty, R.M. (Ed.) (1992), A Linguistic turn: Essays in Philosophical Method. With Two Retrospective Essays, University of Chicago Press, Chicago, IL.

Rose, G. (2011), Visual Methodologies: An Introduction to Researching in Visual Materials, Sage Publications Ltd, London.

Sannö, A., Fundin, A. and Stålberg, L. (2016) "Managing environmental driven change within manufacturing organisations - moving from reactive to proactive behaviour", International Journal of Productivity and Quality Management, Vol. 18, No. 2/3, pp. 347-363.

Sirkin, H.L., Keenan, P. and Jackson, A. (2005), "The Hard Side of Change Management", Harvard Business Review, Vol. 83, No. 10, pp. 108-118.

Shannon, C.E., and Weaver, W. (1949). The Mathematical Theory of Communication, University of Illinois Press Urbana, IL.

Smith, A.C.T. and Stewart, B. (2011), "Organizational Rituals: Features, Functions and Mechanisms”, International Journal of Management Reviews, Vol. 13, No. 2, pp. 113-133.

Spencer, B.A. (1994), "Models of Organization and Total Quality Management: A Comparison and Critical Evaluation", Academy of Management Review, Vol. 19, No. 3, pp. 446-471. 
Staples, D.S., Greenaway, K. and McKeen, J.D. (2001), "Opportunities for research about managing the knowledge-based enterprise", International Journal of Management Reviews, Vol. 3, No. 1, pp. 1-20.

\section{Sturken, M. and Cartwright, L. (2009), Practices of Looking, Oxford University Press, Oxford, UK.}

Styhre, A. (2010), Visual Culture in Organizations: Theory and Cases, Routledge, Abingdon, UK.

Taylor, S. and A. Spicer (2007), "Time for space: A narrative review of research on organizational spaces", International Journal of Management Reviews, Vol. 9, No. 4, pp. 325-346.

Trethewey, A. (1999), "Disciplined Bodies: Women's Embodied Identities at Work", Organization Studies, Vol. 20, No. 3, pp. 423-450.

Tufte E.R. (1997), Visual Explanations: Images and Quantities, Evidence and Narrative, Graphics Press, Cheshire, CT.

Tversky, B. (2011), Visualizing Thought, Topics in Cognitive Science, Vol. 3, No. 3, pp. 499-535.

Ware, C. (2008), Visual Thinking for Design, Morgan Kaufman, Burlington, MA.

Weick, K.E. and Quinn, P. (1999), “Organizational change and development”, Annual Review of Psychology, Vol. 50, pp. 361-386.

Whyte, J.K., Ewenstein, B., Hales, M. and Tidd, J. (2007), "Visual practices and the objects used in design", Building Research and Information, Vol. 35, No. 1, pp. 18-27.

\section{Biographies}

\section{Yvonne Eriksson}

Yvonne Eriksson holding the chair in Information Design and is research director of Innovation and Product Realisation at Mälardalen University. She received a Ph.D. in Art History at Göteborg University 1998. Yvonne Eriksson has been working at the Department of Art History and Visual Studies at Göteborg University, Växjö University (now Linneues university) visiting professor at Royal Institute of Technology, KTH. Her main interest for her research is visual communication, and especially the perceptual and cognitive processes that are involved in interpretation of visuals and build milieus in combination of socio cultural perspective.

\section{Anders Fundin}

Dr Anders Fundin is Professor in Quality Technology and Management at Mälardalen University. His research interest is related with Quality Management, Operations Management and Change Management with operational experience from several managerial positions within the Volvo Group and Bombardier Transportation together with nearly twenty years of research and development experience performed in collaboration with about thirty multinational companies and several universities. The research work is published in 
international journals such as for example International Journal of Service Industry Management, International Journal of Quality and Reliability Management, Journal of Business and Industrial Marketing and International Journal of Productivity and Quality Management. 


\begin{tabular}{|c|c|c|c|c|c|}
\hline \multicolumn{6}{|c|}{ Visuals needed and potential pitfalls when managing an episodic change process } \\
\hline $\begin{array}{l}\text { Stages }(1-8) \text { in an } \\
\text { episodic change } \\
\text { process }\end{array}$ & Visuals needed & $\begin{array}{c}\text { Required } \\
\text { ambidextrous } \\
\text { capabilities (A1) }\end{array}$ & Pitfalls & $\begin{array}{c}\text { Required } \\
\text { ambidextrous } \\
\text { capabilities (A2) }\end{array}$ & $\begin{array}{c}\text { Required } \\
\text { ambidextrous } \\
\text { capabilities (A3) } \\
\text { (next episodic } \\
\text { change is } \\
\text { introduced) } \\
\end{array}$ \\
\hline $\begin{array}{l}\text { Stage 1 } \\
\text { Establish a sense } \\
\text { of urgency }\end{array}$ & $\begin{array}{l}\sqrt{ } \text { Visualization of } \\
\text { weaknesses }\end{array}$ & $\begin{array}{l}\text { Balancing strengths and } \\
\text { weaknesses as equally } \\
\text { important }\end{array}$ & $\begin{array}{l}\sqrt{ } \text { Not visualizing } \\
\text { the strengths }\end{array}$ & & \multirow{4}{*}{$\begin{array}{l}\text { A new cycle of } \\
\text { episodic change is } \\
\text { introduced while } \\
\text { finalizing the last } \\
\text { episode with eight } \\
\text { steps }\end{array}$} \\
\hline $\begin{array}{c}\text { Stage } 2 \\
\text { Form a powerful } \\
\text { guiding coalition }\end{array}$ & $\begin{array}{l}\sqrt{ } \text { Create a picture } \\
\text { of the team } \\
\sqrt{ } \text { The team must } \\
\text { internalize the } \\
\text { future change in } \\
\text { their visual } \\
\text { approach }\end{array}$ & $\begin{array}{l}\text { Team is recognizable, } \\
\text { but still the team } \\
\text { members are integrated } \\
\text { as a part of the } \\
\text { organization }\end{array}$ & $\begin{array}{l}\sqrt{ } \text { Too much } \\
\text { separated from the } \\
\text { organization } \\
\text { (clothing, } \\
\text { appearance, and } \\
\text { always showing up } \\
\text { as a team) } \\
\sqrt{ } \text { Never showing up } \\
\text { as a team }\end{array}$ & $\begin{array}{c}\text { Stage 1-2 } \\
\text { Retain ownership } \\
\text { from stage } 1 \text { and } \\
\text { invitation of } \\
\text { employees in stage } 2\end{array}$ & \\
\hline $\begin{array}{c}\text { Stage } 3 \\
\text { Create a vision }\end{array}$ & $\begin{array}{l}\sqrt{ } \text { Visualize the } \\
\text { weaknesses } \\
\text { through a } \\
\text { combination of the } \\
\text { future } \\
\text { opportunities and } \\
\text { attractive state }\end{array}$ & $\begin{array}{l}\text { Balancing the level of } \\
\text { abstract and tangible } \\
\text { visual formulations of } \\
\text { the future state }\end{array}$ & $\begin{array}{l}\sqrt{ } \text { The visualization } \\
\text { of the future state is } \\
\text { too definite or too } \\
\text { abstract } \\
\sqrt{ } \text { Too much focus } \\
\text { on the visualization } \\
\text { of the weaknesses }\end{array}$ & \multirow{2}{*}{$\begin{array}{c}\text { Stage 3-4 } \\
\text { Retain the abstract } \\
\text { level from stage } 3 \\
\text { while communicating } \\
\text { in stage } 4\end{array}$} & \\
\hline $\begin{array}{c}\text { Stage } 4 \\
\text { Communicate the } \\
\text { vision }\end{array}$ & $\begin{array}{l}\sqrt{ } \text { Strong link } \\
\text { between what is } \\
\text { communicated } \\
\text { visually and } \\
\text { verbally } \\
\sqrt{ } \text { The visual } \\
\text { approach of the } \\
\text { coalition must go } \\
\text { in line with the } \\
\text { vision }\end{array}$ & $\begin{array}{l}\text { Balancing the } \\
\text { communication of the } \\
\text { visual formulation by } \\
\text { keeping the balance } \\
\text { between abstract and } \\
\text { tangible visions of the } \\
\text { future }\end{array}$ & $\begin{array}{l}\sqrt{ } \text { Showing one } \\
\text { thing and talking } \\
\text { about another } \\
\sqrt{ } \text { Too high level of } \\
\text { abstraction of the } \\
\text { visualization of the } \\
\text { future state }\end{array}$ & & \\
\hline $\begin{array}{c}\text { Stage } 5 \\
\text { Empower others to } \\
\text { act on the vision }\end{array}$ & $\begin{array}{l}\sqrt{ } \text { The vision must } \\
\text { be of mimetic } \\
\text { quality } \\
\sqrt{ } \text { The visualization } \\
\text { must enable } \\
\text { internalization }\end{array}$ & $\begin{array}{l}\text { Balancing between } \\
\text { current identity and } \\
\text { future possibilities }\end{array}$ & $\begin{array}{l}\sqrt{ } \text { Not possible to } \\
\text { identify oneself } \\
\text { with the } \\
\text { visualization } \\
\sqrt{ } \text { The visualization } \\
\text { is not in line with } \\
\text { the identity of the } \\
\text { company }\end{array}$ & \multirow{2}{*}{$\begin{array}{l}\text { Stage 5-6 } \\
\text { Retain momentum in } \\
\text { empowerment while } \\
\text { not losing focus on } \\
\text { future wins }\end{array}$} & \multirow{4}{*}{$\begin{array}{l}\text { Manage the } \\
\text { capabilities to } \\
\text { introduce the next } \\
\text { episode by } \\
\text { establishing a } \\
\text { sense of urgency }\end{array}$} \\
\hline $\begin{array}{c}\text { Stage } 6 \\
\text { Plan to create } \\
\text { short-term wins }\end{array}$ & $\begin{array}{l}\sqrt{ } \text { Visualize a first } \\
\text { positive step of the } \\
\text { strategy } \\
\sqrt{ } \text { Visualize how } \\
\text { co-workers have } \\
\text { contributed to the } \\
\text { improvement }\end{array}$ & $\begin{array}{l}\text { Balancing between } \\
\text { short-term wins and } \\
\text { long-term wins as a } \\
\text { leverage on the future } \\
\text { state. Visualize both } \\
\text { strengths and } \\
\text { limitations of short- } \\
\text { term wins }\end{array}$ & $\begin{array}{l}\sqrt{ } \text { The visualization } \\
\text { is too similar to the } \\
\text { final state }\end{array}$ & & \\
\hline $\begin{array}{c}\text { Stage } 7 \\
\text { Consolidate } \\
\text { improvements and } \\
\text { produce more } \\
\text { change }\end{array}$ & $\begin{array}{l}\sqrt{ } \text { Visualize the } \\
\text { improvement in } \\
\text { line with the } \\
\text { previous step }\end{array}$ & $\begin{array}{l}\text { Balancing the actual } \\
\text { results and required } \\
\text { remaining work } \\
\text { towards the future state }\end{array}$ & $\begin{array}{l}\sqrt{ } \text { The visualization } \\
\text { drives in a new } \\
\text { direction and loses } \\
\text { the link to the } \\
\text { visualization of the } \\
\text { future state }\end{array}$ & \multirow[b]{2}{*}{$\begin{array}{c}\text { Stage 7-8 } \\
\text { Retain momentum of } \\
\text { change and at the } \\
\text { same time internalize } \\
\text { the change }\end{array}$} & \\
\hline $\begin{array}{c}\text { Stage } 8 \\
\text { Institutionalize } \\
\text { new approaches }\end{array}$ & $\begin{array}{l}\sqrt{ } \text { Visualization of } \\
\text { the new state in } \\
\text { line with the } \\
\text { previously } \\
\text { visualized vision } \\
\sqrt{\text { The visualization }} \\
\text { is possible to } \\
\text { expand and is } \\
\text { being more } \\
\text { detailed }\end{array}$ & $\begin{array}{l}\text { Balancing the previous } \\
\text { desired state of the } \\
\text { future with the new } \\
\text { current state }\end{array}$ & $\begin{array}{l}\sqrt{ } \text { The visualization } \\
\text { is leaving the } \\
\text { previous design of } \\
\text { the visualization }\end{array}$ & & \\
\hline
\end{tabular}

